\title{
Introduction: Modelling compound properties
}

\author{
Sabine Arndt-Lappe ${ }^{1}$ (D) Melanie J. Bell ${ }^{2}$. \\ Martin Schäfer ${ }^{3}$. Barbara Schlücker ${ }^{4}$
}

Received: 4 March 2016/ Accepted: 7 March 2016 / Published online: 17 March 2016

(C) Springer Science+Business Media Dordrecht 2016

\section{Introduction}

In the study of linguistic morphology, a great deal of interest has been directed towards the properties of compounds. The term 'properties' is taken here to have wide scope, including all aspects of a compound's form and meaning as well as factors that influence compound processing, production or acquisition. Recent evidence of this interest can be seen, for example, in the publication of The Oxford Handbook of Compounding (Lieber and Štekauer 2009) as well as several other collected volumes, including Libben and Jarema (2006), Gaeta and Grossmann (2009), Scalise and Vogel (2010) and Gaeta and Schlücker (2012).

Much of the contemporary research is characterised by data-rich empirical work, which has managed to shed new light on compound properties that have hitherto defied adequate description. This is especially true for semi-systematic and gradient properties including, for example, the selection of linking elements (Krott et al. 2007)

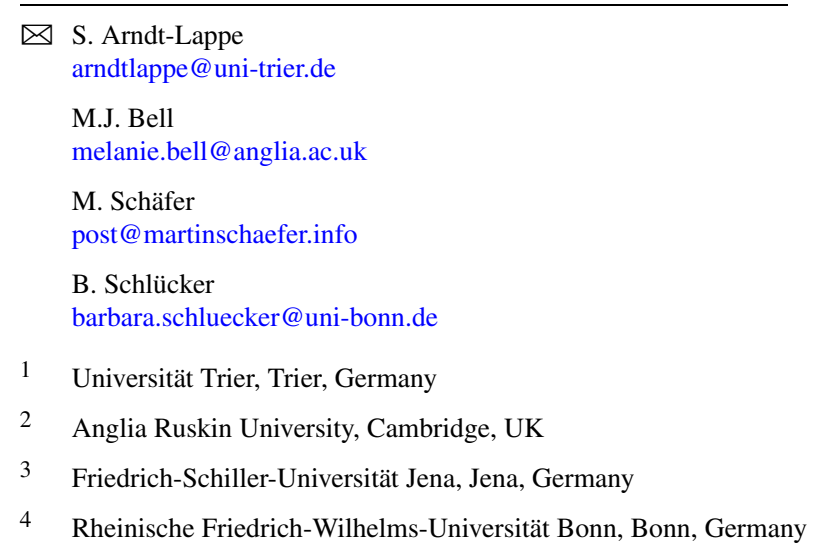


and their phonetic realisation (Kuperman et al. 2007), speakers' choice of particular morphological forms (Ramscar and Dye 2011; Schlücker and Plag 2011) and spelling variants (Kuperman and Bertram 2013), semantic patterns (Maguire et al. 2010) and semantic transparency (Bell and Schäfer 2013), compound comprehension (Gagné and Spalding 2014), stress placement (Arndt-Lappe 2011; Bell and Plag 2012) and the boundary between morphological compounds and syntactic phrases (Baroni et al. 2009; Bell 2012). Such work exhibits a variety of approaches employing large-scale data sources, a number of experimental methods and a diversity of computational modelling techniques. Crucially, such approaches have not only been used as tools to provide adequate formal or mathematical representations of the data, but have also led to the development of new explanations of compound properties.

This special issue of Morphology grew out of a workshop organised by the editors at the 16th International Morphology Meeting in Budapest in May 2014. The aim of the workshop was to take stock of the variety of methods being used to model compound properties, to promote discussion of the explanatory aspects of the models produced, and to evaluate their compatibility with one another. The issue presents a selection of papers from this workshop, which illustrate a range of compound properties meriting investigation, as well as the different perspectives from which these properties can be explored. Perhaps not surprisingly, it is the most elusive property of compounds that re-occurs in all four papers, albeit in different forms: namely, the looseness of the link between their formal characteristics and their semantic interpretation. The paper by Pavel Štichauer shows that this dissociation is nothing new diachronically. The papers by Gagné and Spalding and Bell and Schäfer show that, despite the looseness of the connection, human subjects do exploit links between compound form and meaning. Finally, the paper by Kunter and Plag argues that the link between form and meaning might not be so loose as previously thought.

In the first paper, Pavel Štichauer uses a combination of lexicographic and corpus data to investigate the diachronic development of Italian verb-noun compounds from the 16 th to the 19 th centuries. He shows that, during this period, the verb-noun form has been associated with four different semantic construals: agentive, instrumental, locative and eventive. However, in the last 200 years, the instrumental construal has become more productive, resulting in a large increase in the number of verb-noun compound types in the language. Štichauer argues that the availability of the different interpretations has remained constant, while the extent to which they have been exploited has changed. In other words, there has always been dissociation between the formal properties of the pattern and its semantic interpretation, but the productivity of the different construals has varied over time.

Christina Gagné and Thomas Spalding measure typing speeds to investigate the effects of semantic transparency and semantic priming on the written production of unspaced two-part English compound nouns. They show that typing slows down at the boundaries between constituents, which they interpret as evidence that morphemic information is used during production. Typing times are also affected by semantic priming of the modifier and by the semantic transparency or opacity of both constituents; furthermore, these effects interact so that, for example, the effect of semantically priming the modifier depends on the transparency of the head. In some cases, semantic priming is even found to speed up the production of opaque constituents. 
Overall, the authors interpret their results as supporting the 'maximisation of opportunity' view of the language processing system: although the link between form and meaning is loose, the system makes maximum and opportunistic use of the information that is available.

While semantic transparency plays an important role in Gagné and Spalding's paper, its very nature is the focus of the paper by Melanie Bell and Martin Schäfer, who provide statistical models of human semantic transparency ratings of English noun-noun compounds and their individual constituents. The models show that transparency is positively correlated with the frequency of the first noun as a free form, with the extent to which the compound's semantic relation is typically associated with the first noun, and with the productivity of the second noun as a compound head. The authors interpret these findings as evidence that perceived transparency is a reflex of the degree to which the internal semantic structure of the compound is expected. Whereas Gagné and Spalding see transparency as a predictor of processing speed, Bell and Schäfer use their results to argue that ease of processing may actually underlie perceptions of transparency. However, both papers support the idea that human subjects use formal and semantic properties of the constituents to build informed hypotheses about a compound's meaning, and that the properties of the different constituents interact in this process.

In the final paper of our special issue, Gero Kunter and Ingo Plag use acoustic data to investigate whether the internal structure of English triconstituent compounds is reflected in their phonetic realisation. On the assumption that these constructions involve the combination of an embedded two-part compound with a third, non-embedded constituent, they show that the non-embedded constituent tends to be lengthened while the adjacent embedded constituent tends to be shortened. The authors interpret this as evidence that morphological structure is reflected in the speech signal. However, given that this structure is established on the basis of a compound's interpretation, the results also demonstrate a relationship between semantic structure and phonetic realisation.

Taken together, the papers in this issue show that, although there is not and probably never has been a one-to-one correspondence between the form and meaning of compounds, the form does provide a wide variety of information to which humans have access in reaching an interpretation. This information includes the semantics of the constituents as free forms, their semantic relations to other compound constituents, their distribution in the language and their phonetic realisation. Although contextual information and world knowledge undoubtedly play major roles in the interpretation of compounds in actual use, this compound-external information must interact with the kind of inherent information discussed in this issue. The papers also demonstrate the range of empirical data and approaches that can contribute to teasing apart the very complex, yet for speakers seemingly effortless, processes involved in compounding.

\section{References}

Arndt-Lappe, S. (2011). Towards an exemplar-based model of stress in English noun-noun compounds. Journal of Linguistics, 47(11), 549-585. 
Baroni, M., Guevara, E., \& Zamparelli, R. (2009). The dual nature of deverbal nominal constructions: evidence from acceptability ratings and corpus analysis. Natural Language and Linguistic Theory, 5(1), 27-60.

Bell, M. J. (2012). The English noun-noun construct: a morphological and syntactic object. In A. Ralli, G. Booij, S. Scalise, \& A. Karasimos (Eds.), Proceedings of the 8th international morphology meeting. Morphology and the architecture of grammar (pp. 59-91). Patras: University of Patras. http://morbo.lingue.unibo.it/mmm.

Bell, M. J., \& Plag, I. (2012). Informativeness is a determinant of compound stress in English. Journal of Linguistics, 48(3), 485-520.

Bell, M. J., \& Schäfer, M. (2013). Semantic transparency: challenges for distributional semantics. In A. Herbelot, R. Zamparelli, \& G. Boleda (Eds.), Proceedings of the IWCS 2013 workshop: Towards a formal distributional semantics (pp. 1-10). Potsdam: Association for Computational Linguistics.

Gaeta, L. \& Grossmann, M. (Eds.) (2009). Compounds between syntax and lexicon. Special Issue of Italian Journal of Linguistics/Rivista Di Linguistica, 21(1).

Gaeta, L. \& Schlücker, B. (Eds.) (2012). Das Deutsche als kompositionsfreudige Sprache. Strukturelle Eigenschaften und systembezogene Aspekte. (Linguistik - Impulse \& Tendenzen 46). Berlin/New York: De Gruyter.

Gagné, C., \& Spalding, T. (2014). Conceptual composition: the role of relational competition in the comprehension of modifier-noun phrases and noun-noun compounds. In B. H. Ross (Ed.), The psychology of learning and motivation (pp. 97-130). New York: Elsevier.

Krott, A., Schreuder, R., Baayen, H. R., \& Dressler, W. U. (2007). Analogical effects on linking elements in German compounds. Language and Cognitive Processes, 22(1), 25-57.

Kuperman, V., \& Bertram, R. (2013). Moving spaces: spelling alternation in English noun-noun compounds. Language and Cognitive Processes, 28(7), 939-966.

Kuperman, V., Pluymaekers, M., \& Ernestus, M. (2007). Morphological predictability and acoustic duration of interfixes in Dutch compounds. The Journal of the Acoustical Society of America, 121(4), 2261-2271.

Libben, G. \& Jarema, G. (Eds.) (2006). The representation and processing of compound words. Oxford/New York: Oxford University Press.

Lieber, R. \& Štekauer, P. (Eds.) (2009). The Oxford handbook of compounding. Oxford/New York: Oxford University Press.

Maguire, P., Wisniewski, E. J., \& Storms, G. (2010). A corpus study of semantic patterns in compounding. Corpus Linguistics and Linguistic Theory, 6(1), 49-73.

Ramscar, M., \& Dye, M. (2011). Learning language from input: why innate constraints can't explain noun compounding. Cognitive Psychology, 62(1), 1-40.

Scalise, S. \& Vogel, I. (Eds.) (2010). Cross-disciplinary issues in compounding. Amsterdam/Philadelphia: John Benjamins.

Schlücker, B., \& Plag, I. (2011). Compound or phrase? Analogy in naming. Lingua, 121(9), 1539-1551. 